\title{
Evaluation of altmetrics indicators of Birjand University of Medical Sciences articles listed on the Scopus Database by using the PlumX Tool: A Scientometric Study
}

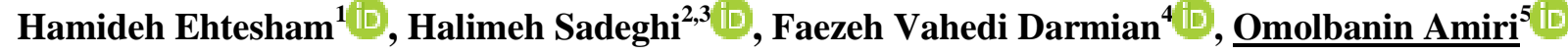 \\ ${ }^{I}$ Department of Health Information technology, Birjand University of Medical Sciences, Birjand, Iran. \\ ${ }^{2}$ Central Library, Birjand University of Medical Sciences, Birjand, Iran \\ ${ }^{3}$ candidate of Information and Knowledge Science, Ferdowsi University, Mashhad, Iran \\ ${ }^{4}$ Scientometrics and Monitoring Group, Birjand University of Medical Sciences, Birjand, Iran \\ ${ }^{5}$ Corresponding author; Scientometrics and Monitoring Group, Birjand University of Medical Sciences, Birjand, Iran \\ Tel: +985632381753 Email: amiri@bums.ac.ir
}

Citation Ehtesham H, Sadeghi H, Vahedi Darmian F, Amiri O. [Evaluation of altmetrics indicators of Birjand
University of Medical Sciences articles listed on the Scopus Database by using the PlumX Tool: A
Scientometric Study]. J Birjand Univ Med Sci. 2019; 26(4): 343-52. [Persian]

\begin{abstract}
Background and Aim Altmetrics indicators, to measure different aspects of an effect, was created in social media environments. The purpose of the present study was to investigate the altmetrics indicators of Birjand University of Medical Sciences articles registered in Scopus database.

Materials and Methods: This research was a descriptive-analytical one which was done by using a scientometric method and using altmetrics indicators. Data collection was performed on 16 July 2019 by searching the titles of articles in Birjand University of Medical Sciences individually in the Scopus database based on plumX indicators (use, acquisition, discussion, social media and citation) and extracted indicators for 2 weeks. Pearson's correlation coefficient was used to analyze the data.

Results: Of 911 retrieved articles, overal 89 percent were shared on social media at least once. The maximum frequency of the index belonged to the reader parameter, which is a subset of the acquisition index. Birjand University of Medical Sciences articles received the most amount of attention in the Mendeley network. There was a significant relationship between the amount of citations of articles and the degree of acquisition $(r=0.286, \mathrm{P}<0.001)$.There was no significant relationship between the amount of citations received in the Scopus database and the discussion index $(\mathrm{r}=-0.048, \mathrm{P}=0.820)$.
\end{abstract}

Conclusion: Altmetrics indicators or alternative metrics can be a suitable complement to citation analysis. Consideration of these indicators in the publication of articles by researchers can be effective in obtaining citation articles.

Key Words: Altmetrics Indicators; Articles; Birjand University of Medical Sciences; Scientometrics 


\section{بروسى شاخصهاى آلتمتريكس مقالات دانشكاه علوم يزشكى بيرجن منلفرج در يايكاه Scopus با استفاده از ابزار PlumX: يك مطالعه علمسنجى}

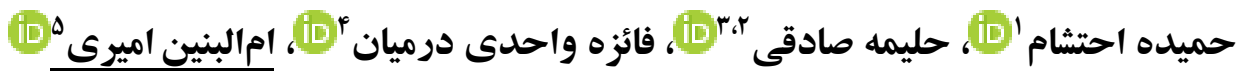

جـ

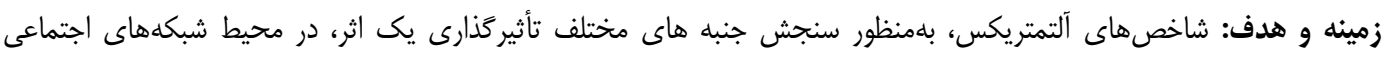

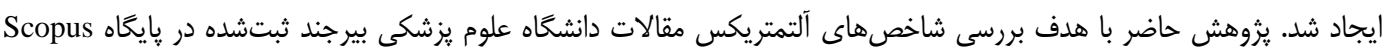

انجام شد.

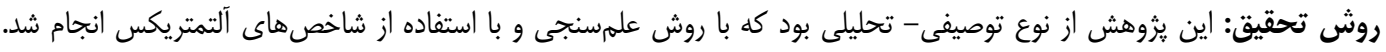

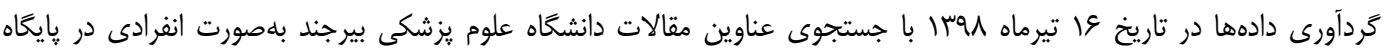
Scopus

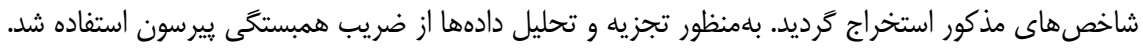

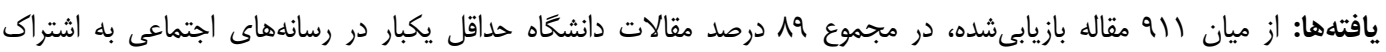

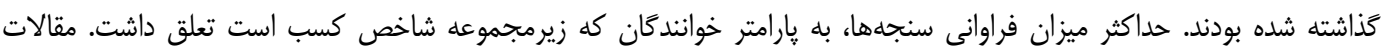

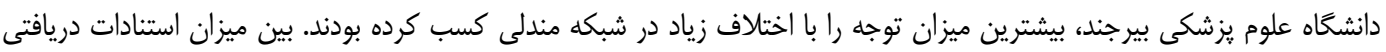

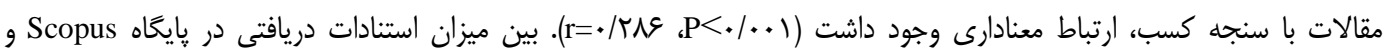

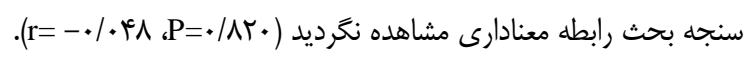

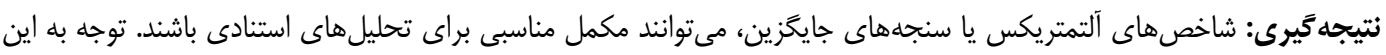

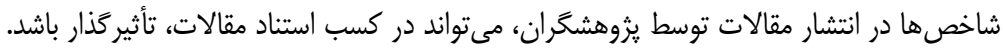
وازههاى كليدى: شاخصهاى آلتمتريكس؛ مقالات؛ دانشكاه علوم بزشكى بيرجند؛ علمسنجى

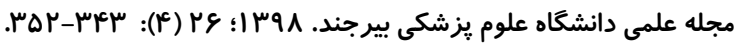

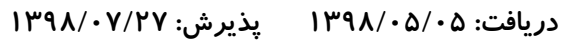

'كروه فناورى اطلاعات سلامت، دانشخاه علوم يزشكى بيرجند، بيرجند، ايران

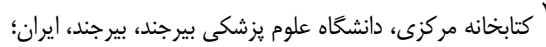

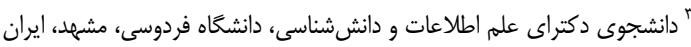

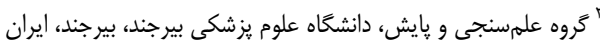

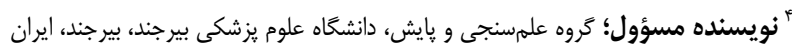

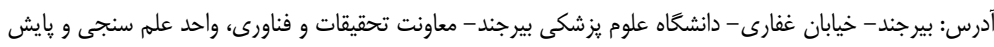

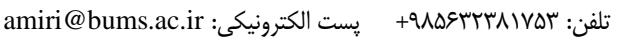




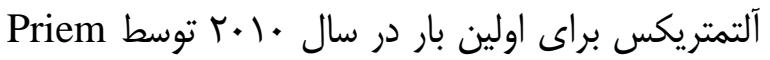
مقدمه

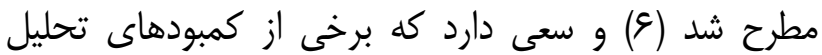

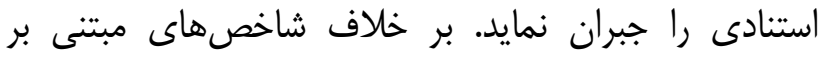

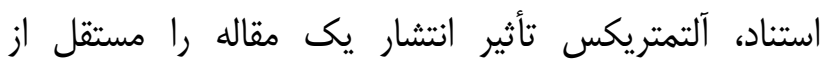

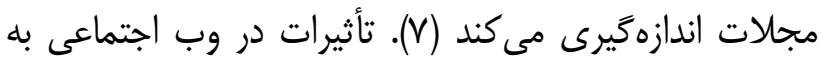

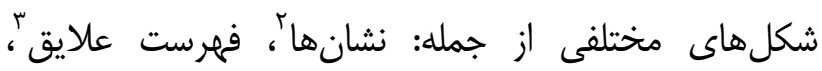

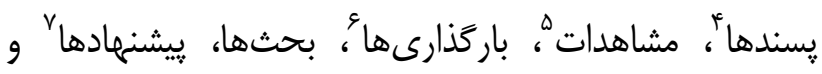

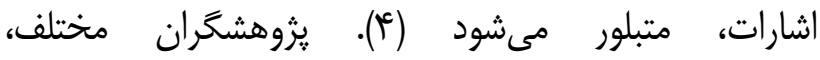
دستلبندى هاى متفاوتى را از سنجهات مهاى جايخزين اردائه كردهاند. در طبقلبندى كه سايت Plum Analytics در سال

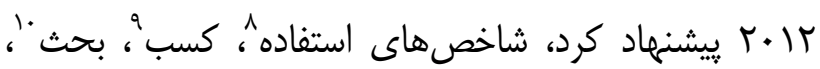

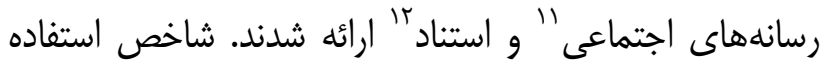

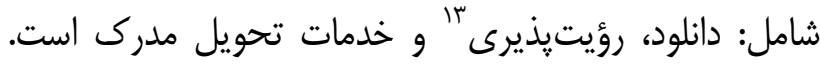
شاخص كسب مواردى جون: علاقمندى، نشانه گذارى، ذخيره

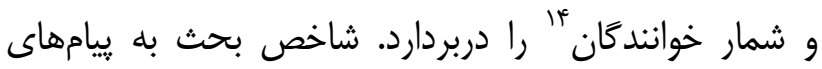

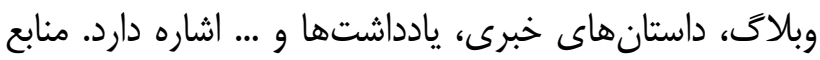
داده براى محاسبه اين سنجه عبارتند از: Facebook، Wikipedia Google Plus وبلاكَهاى علمى و غيره. در شاخص رسانههاى اجتماعى،

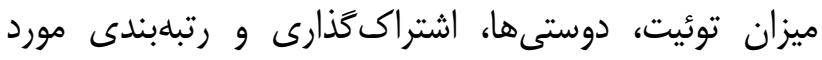

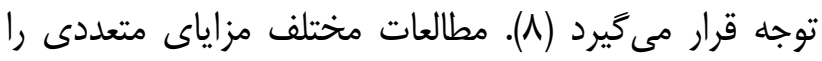
براى شاخصهاى آلتمتريكس برشمردهاند كه كمك به به سامانه

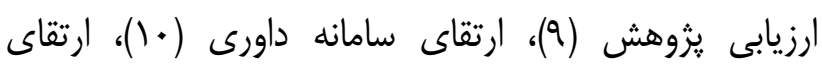

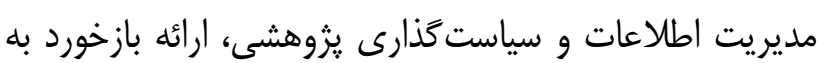

\footnotetext{
${ }^{2}$ Book marks

${ }^{3}$ Favorites

${ }^{4}$ Likes

5 Views

${ }^{6}$ Downloads

${ }^{7}$ Recommendations

${ }^{8}$ Usage

${ }^{9}$ Capture

${ }^{10}$ Mention

${ }^{11}$ Social Media

${ }^{12}$ Citation

${ }^{13}$ Visibility

${ }^{14}$ Readers
}

از مهمترين ابزارهاى ارزيابى يزوهش، نمايههاى استنادى

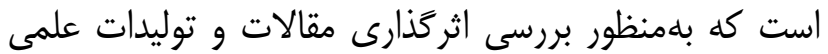

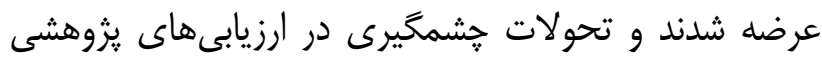

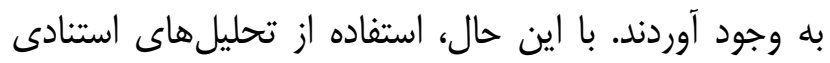

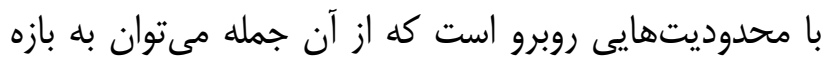

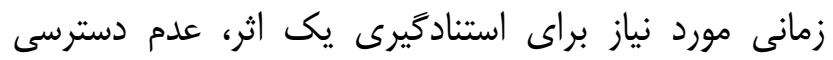

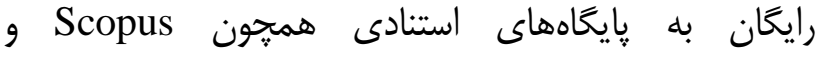
Web of Sciences تأثيرات خود استنادى و استناد منفى اشاره كرد (1) (1).

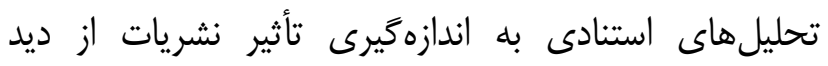

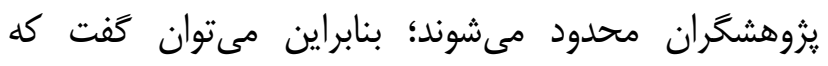

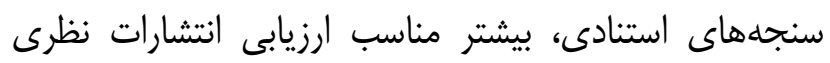

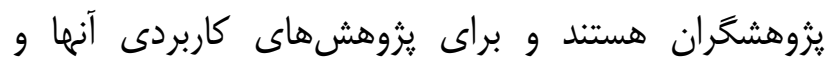

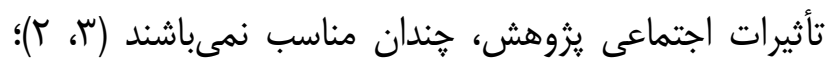

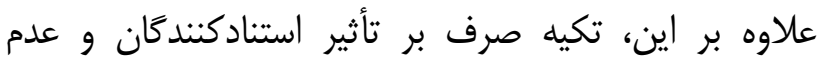

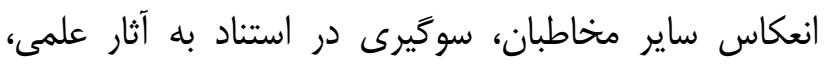
تفاوت در نرخ استنادها (با توجه به نوع انتشارات، بازه زمانى،

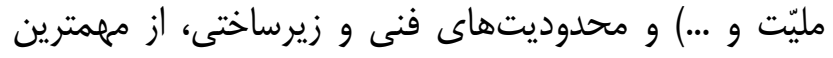

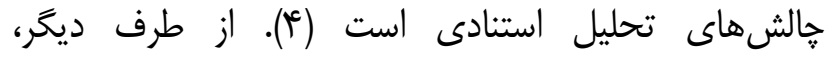
ييشرفتهاى فناورى اطلاعات و ارتباطات، ظهور تكنولوزى إنى

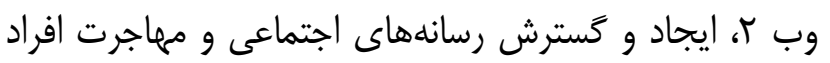

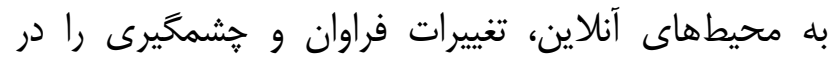

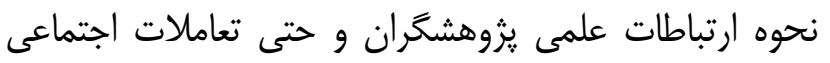

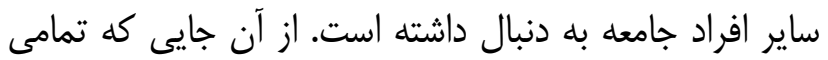

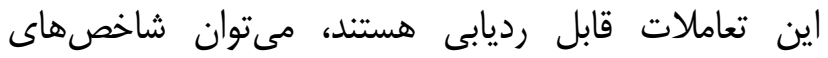

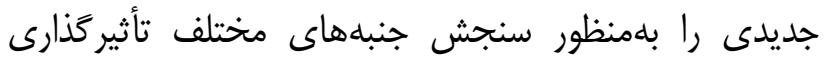

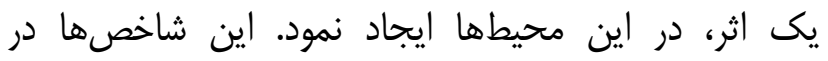

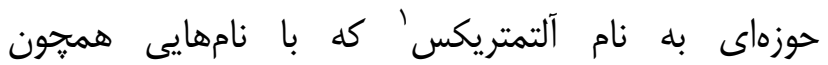
شاخصهاى جايخزين يا دخرسنجهها نيز شناخته مىشود، قرار

مى گيرد (ه) (ه)

${ }^{1}$ Altmetrics 
مقالات دانشگاه علوم يزشكى گيلان در دو شبكه اجتماعى Research Gate

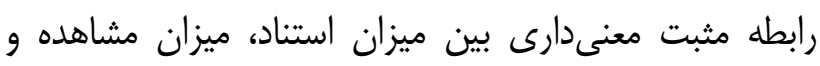

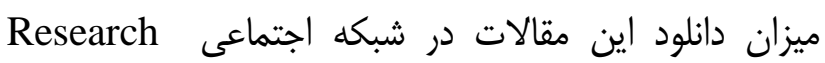
Gate

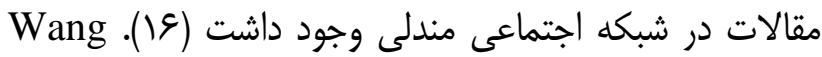

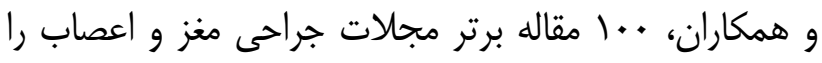

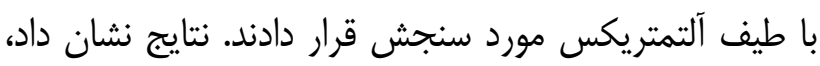

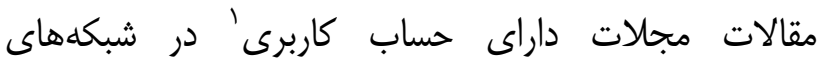
اجتماعى، در مقايسه با مجلات بدات داتل دارن اكانت نمره آلتمتريكس

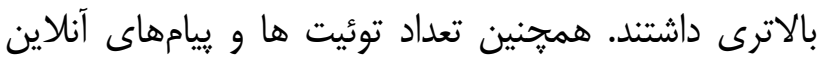
در News athletes، قوىترين ارزش همبستخى را با بمرين لمدرات آلتمتريكس داشتند (IV). Barbic و همكاران مقالات حوزيه

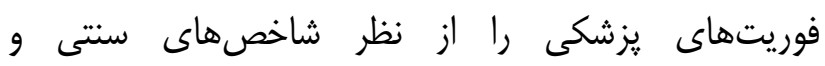
آلتمتريكس مورد مطالعه قرار دادند. بر اساس نتايج استخراج

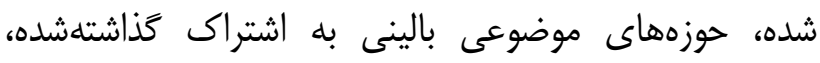

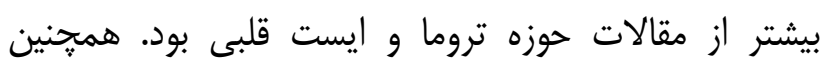
ارتباط مثبت ضعيف بين ميزان استناد دريافتى مقالات و نمره

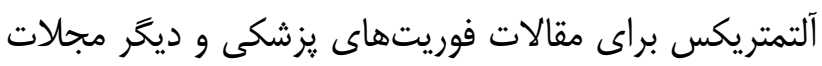

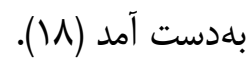

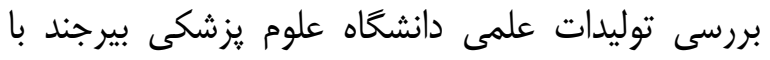
استفاده از شاخصهاى سنتى، نشان داد كه روند رشد توليدات

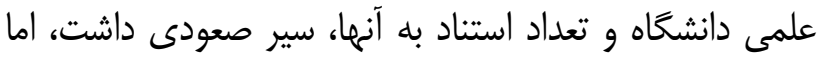

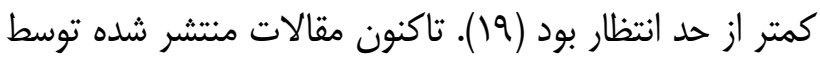

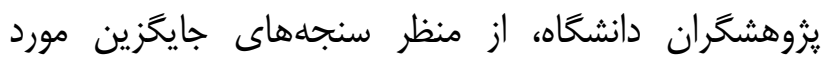

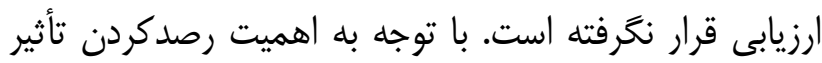
مقالات علمى در شبكههاى اجتماعى و استفاده از اين ابزارها

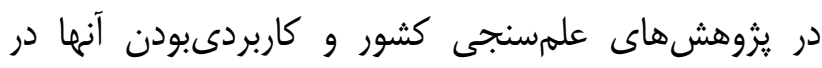

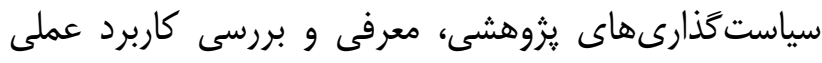

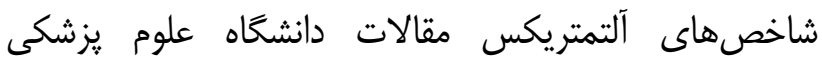

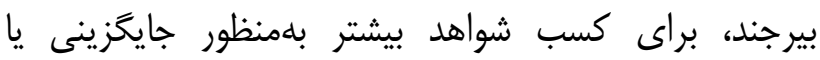

\footnotetext{
${ }^{1}$ Account
}

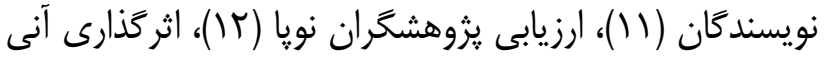
حوزههاى كم استناد، و تمايز بين سنجش استفاده، كيفيت و تأثير (1) از آن آن جمله هستند. با توجه به اهميت شاخص هاى آلتمتريكس و دخرسنجهيها

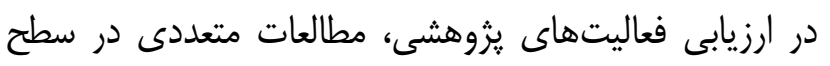

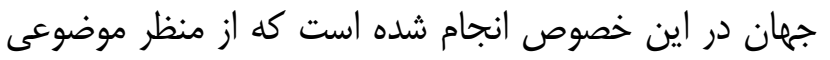

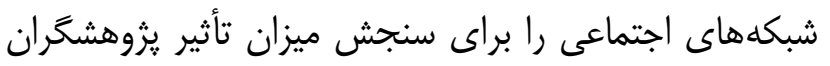

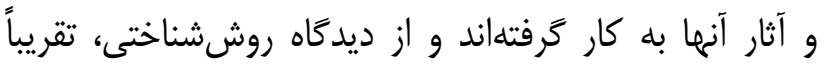
تمام يزوهشها از يك روش واحد يعنى آلتمتريكس استفاده كردهاند و ارتباط آن را با شاخصهاى ئر استنادى سنجيدهاند.

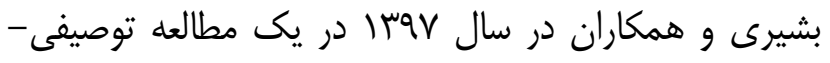
تحليلى با استفاده از شاخصهاى على علمسنجى، ميزان توجه بله مقالات يراستناد علوم يزشكى كشور در بايغاه استنادى علوم

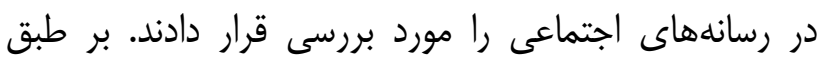

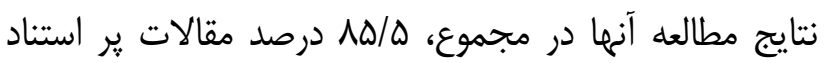

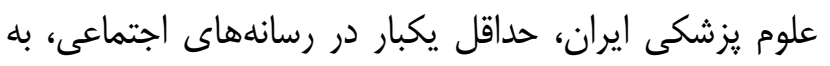
اشتراى كذاشته شده بودند. در بازه زمانى مطالعه آنها، ابزار

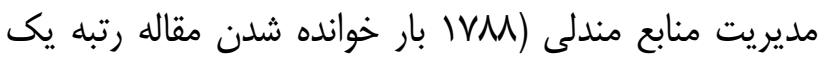

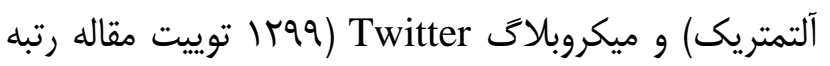
يك آلتمتريك)، مهمترين رسانههاى اجتماعى منتشروكل كنتنده

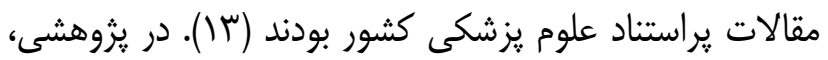

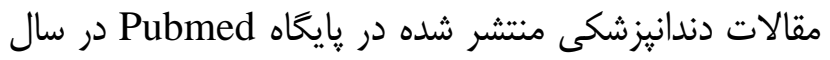

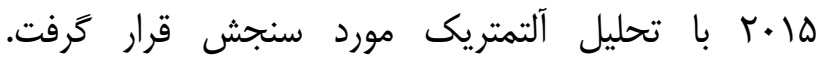
عمدهترين منابع داده آلتمتريكس بلمترتيب: مندلى، Facebook

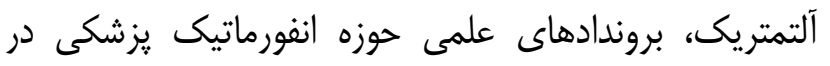

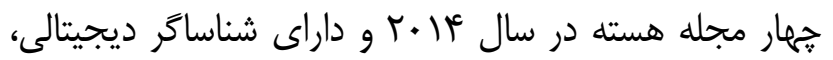

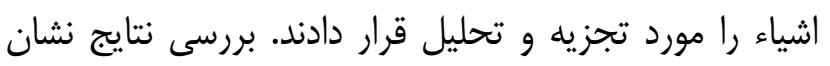

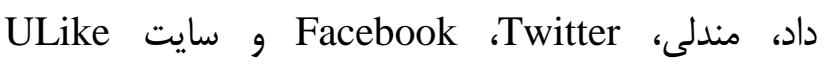
مهمترين رسانههاى مورد استفاده يزوهشگَران براى اشاعه بروندادهاى علمى بودند (ه) (1). اسماعيليور بندبنى و همكاران در يزوهشى، تأثير شاخصى عاى آلتمتريك در ميزان استناد به به 
انتخاب نوع فيلد جستجوى وابستخى سازمانى و و تعيين بازه

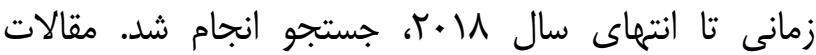

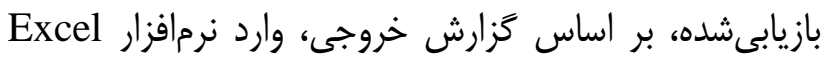

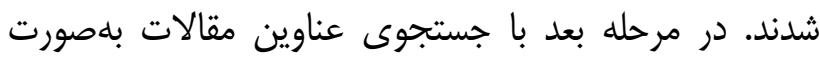
انفرادى در يايخاه Scopus و انتخاب يروفايل هر مر مقاله،

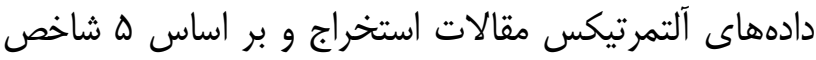
plumX استناد) مقادير متغيرها در سياهه وارسى ثبت گرديد؛ سيس بر برس اساس شاخصهاى PlumX، براى هر مقاله و مجموع امتيازات داده شده، يك نمره آلتمتريك كلى كه نشاندان بهنداء

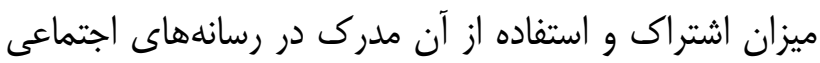

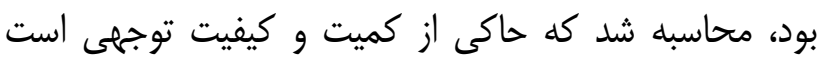
كه يك مدرى در رسانههاى اجتماعى دريافت نموده است.

در راستاى بررسى فرضيه يزوهش و بلممنظور تجزيه و

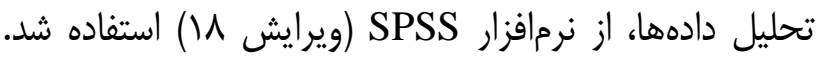

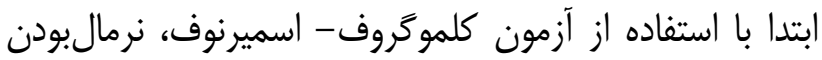

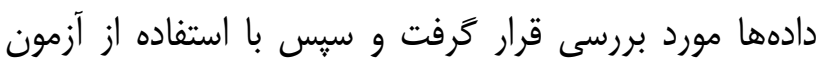

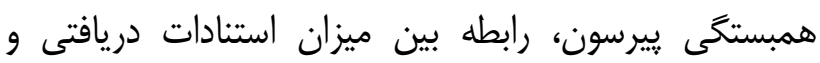

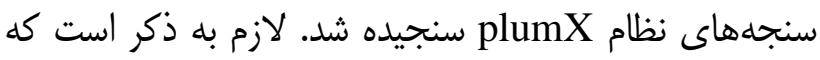

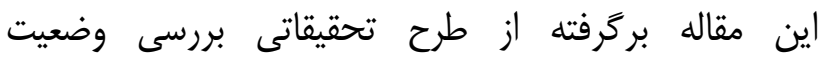

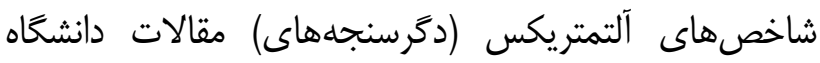
علوم يزشكى بيرجند با شماره ثبت IR.BUMS.REC.1398.163

يافته ها

بررسى نتايج حاصل از استراتزى جستجو، نشان داد كه از ميان مقاله در هيجكدام از رسانههاى اجتماعى مورد استفاده قرار

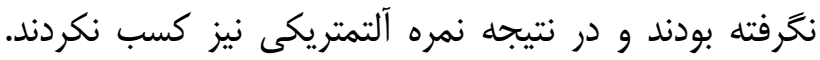
روند ميزان توجه به مقالات در رسانههاى اجتماعى در بازه

${ }^{2}$ Affiliation
استفاده تكميلى از آنها در ارزيابى يُوهشخران، ضرورى به

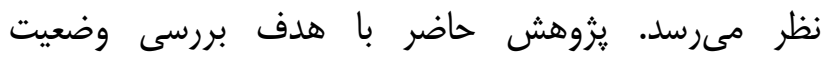
شاخصهاى آلتمتريكس مقالات دانشگاه علوم يزشكى بيرجند

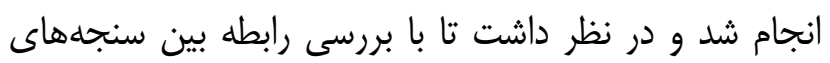

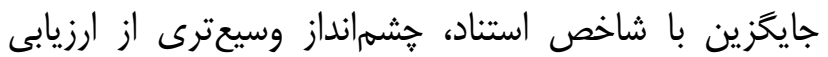

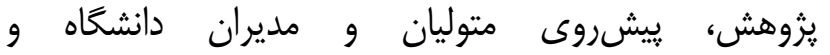

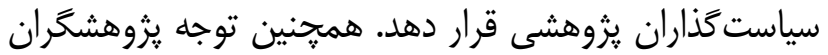
را به بهرهگيرى از قابليتهاى رسانههاى اجتماعى و كاربرد سنجهاى جايخزين در ارزيابىهاى يزوهشى جلب نمائ نمايد.

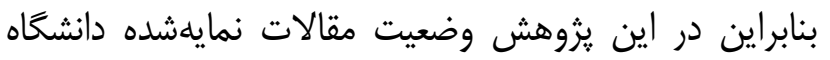

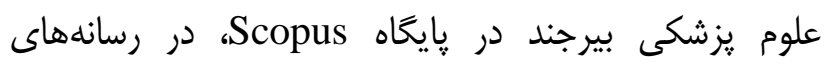

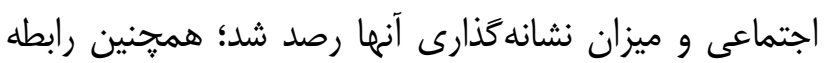

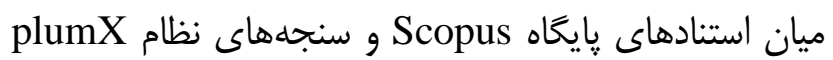
مورد بررسى قرار خرفت.

يزوهش حاضر از لحاظ هدف يك مطالعه كاربردى و از

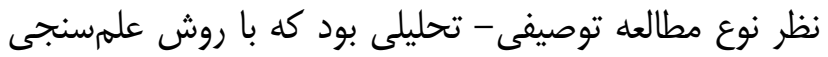

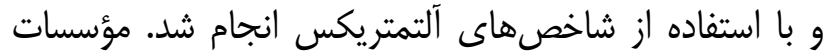

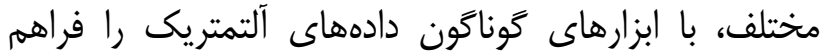

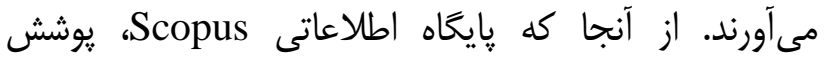

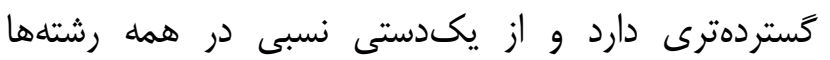
برخوردار است و نيز داراى اهميت ويثزاى در درد سامانه علمسنجى وزارت بهداشت، درمان و آموزش يزشكى است،

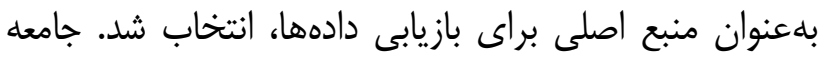

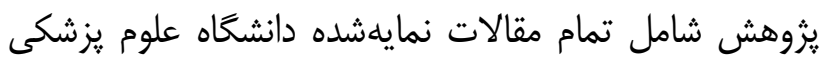

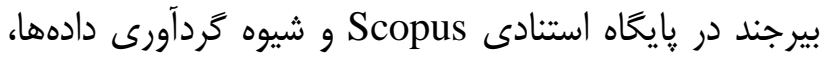
مشاهده بود.

بلمنظور گردآورى دادهها، در تاريخ عا بود تيرماه يوسا، عبارت "Birjand University of Medical Sciences" در جعبه جستجوى اسناد' پِيگاه Scopus وارد و سيس بار

\footnotetext{
${ }^{1}$ Document
} 


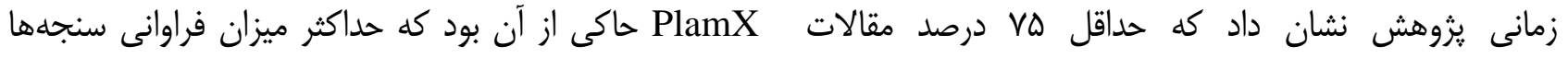

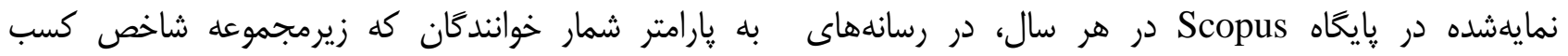

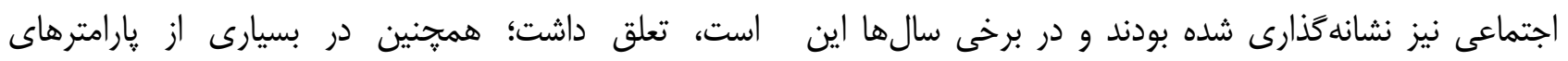

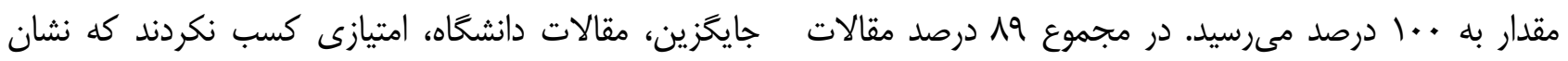

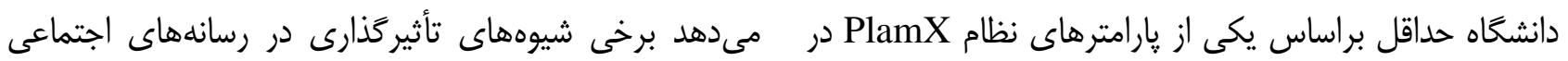

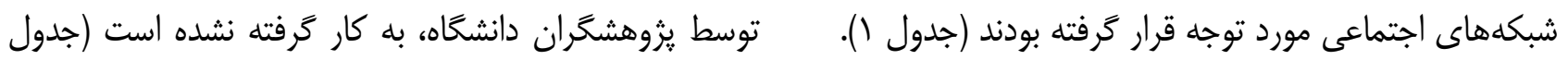

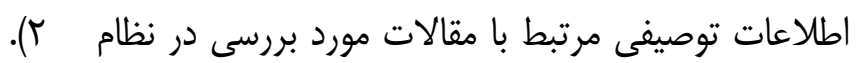

جدول ا - آمار توصيفى سنجش مقالات دانشخًاه علوم يزشكى بيرجند به تفكيك دوره زمانى

\begin{tabular}{|c|c|c|c|c|c|c|}
\hline \multirow{2}{*}{ ميانغَين نمره دَّر سنجى } & \multirow{2}{*}{ دَّروع نمره } & \multicolumn{2}{|c|}{ مقالات داراى نمره دَّر سنجى } & \multirow{2}{*}{ تعداد استنادات } & \multirow{2}{*}{ تعداد مقالات } & \multirow{2}{*}{ سال } \\
\hline & & درصد & فراوانى & & & \\
\hline v & 15 & $1 .$. & r & r & r & $r . . r$ \\
\hline rq & $\wedge \vee$ & $V \Delta$ & r & il & r & $r . . r$ \\
\hline $11 / 18$ & $q V$ & $\Lambda \Delta$ & 9 & rI & v & $r \cdots \Delta$ \\
\hline$v q / s$ & rqu & $1 \ldots$ & $\Delta$ & 99 & $\Delta$ & $r . . r$ \\
\hline $1 . / \Delta V$ & $v^{e}$ & $1 \ldots$ & v & سז & v & $r \ldots v$ \\
\hline 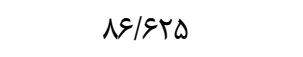 & & $\wedge$. & 19 & TMI & $r$. & $r \cdots \Lambda$ \\
\hline$\Lambda F$ & מאזו & $M$ & 19 & TE & $M$ & $r \ldots q$ \\
\hline ه.s/r山 & girv & 90 & r. & . & r) & $r \cdot 1$. \\
\hline$\$ 9 / 9$ & IQH & 94 & سז & ra. & מ & $r \cdot 11$ \\
\hline MTr/g & $1198 \pi$ & 94 & rv & אזא & f. & $r \cdot I r$ \\
\hline 119 & 819 & $\Lambda$ & $\Delta T$ & rog & $\Delta 9$ & $r \cdot 1 r$ \\
\hline$V \cdot / / r$ & $19 . q$ & $\Lambda \Delta$ & v. & Fin & ᄉr & $r \cdot 1 f^{c}$ \\
\hline $\mid \notin \varepsilon / 40$ & Irvet & 94 & $\wedge \vee$ & rqq & 94 & $r \cdot 10$ \\
\hline $1.1 / T^{f}$ & IrVGq & 94 & وسו & 819 & lef & $r \cdot 19$ \\
\hline G & IVIFV & 90 & وسו & rqV & TE & $r \cdot I V$ \\
\hline $\mid 9 F / T 1$ & & $\wedge$ & $M$ & rov & זسז & $r \cdot M$ \\
\hline - & & 19 & 114 & סמזו & 911 & مجموع \\
\hline
\end{tabular}


جدول ؟- آماره هاى توصيفى مقالات براساس ينج شاخص آلتمتريكس در نظام يلاس

\begin{tabular}{|c|c|c|c|c|c|c|}
\hline حداكثر & حداقل & ميانحَين & درصد & فراوانى & يارامترهاى شاخص & $\begin{array}{l}\text { شاخصهاى } \\
\text { plam x }\end{array}$ \\
\hline fivi & 1 & $99 / 15$ & $\% \Delta T / T \Delta$ & eVg & مشاهده קكيده & \multirow{6}{*}{ استفاده } \\
\hline iq & 1 & $\omega / \&$. & $\% / 9 \vee$ & $M$ & كليك & \\
\hline ITM & 1 & 199 & $\% / .9$ & 9 & دانلود & \\
\hline$w r \cdot$ & 1 & IDF/VA & $\% I V / r r$ & 101 & مشاهده متن كامل & \\
\hline ITE. & 1 & $r r / g$. & \% \%r/gq & $r \cdot v$ & ي ييوندها & \\
\hline$v$ & rv & $\Delta \Gamma / \Delta \cdot$ & $\% \cdot / r)$ & $r$ & مشاهدات & \\
\hline- & - & - & - & $\cdot$ & ن نشانها & \multirow{7}{*}{ كسب } \\
\hline- & - & - & - & . & علاقهمندىها & \\
\hline- & - & - & - & · & دنبال كنندًان & \\
\hline (Iום & • & $\mid f / \Delta \Lambda$ & $\% v r / \wedge v$ & $g V r$ & شمار خوانندكان & \\
\hline ovq & 1 & $\mid \& / T \Delta$ & $\% r M / \Delta$ & TAV & ذخيرهها & \\
\hline- & - & - & - & · & مشتر كين & \\
\hline- & - & - & - & - & بينداًان & \\
\hline r & 1 & $1 / 94$ & $\% 1 / .9$ & 1. & يادداشتهاى وبلاك & \multirow{7}{*}{ بحث } \\
\hline r & r & r & $\% \cdot / 1$ & 1 & يادداشتها & \\
\hline- & - & - & - & . & 'موضوعات انجمنها' & \\
\hline- & - & - & - & . & خلاصهها' & \\
\hline r. & 1 & $\varphi / \Delta \varphi$ & $\% 1 / v a$ & 19 & يادداشتهاى خبرى & \\
\hline- & - & - & - & • & ل لينكها & \\
\hline- & - & - & - & $\cdot$ & بررسىها & \\
\hline AVG & 1 & $I T / \mu V$ & $\% 19 / 49$ & 10. & توئيتها & \multirow{5}{*}{ اجتماعهى } \\
\hline- & - & - & - & . & ي ييشنهادها & \\
\hline- & - & - & - & . & رتبهبندىها' & \\
\hline$r \cdot r$ & 1 & $10 / \mu F$ & $\% \Delta / V$ & ar & به اشتراك كذارىها؟ & \\
\hline- & - & - & - & . & يسندها & \\
\hline v. & 1 & $V / r)$ & $\%$ rI/rA & $r \wedge \Delta$ & ارجاع متقابله & \multirow{2}{*}{ استناد } \\
\hline ع & . & $9 / \Delta q$ & $\% \Leftarrow \Delta / \mathcal{M}$ & 411 & 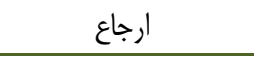 & \\
\hline
\end{tabular}

${ }^{1}$ Forum topic count

2 Gist count

${ }^{3}$ Ratings

4 Shares

${ }^{5}$ Cross-referencing 
جدول بـ سهم رسانه هاى اجتماعى در به اشتراك كذارى مقالات داراى نمره آلتمتريك

\begin{tabular}{|c|c|c|c|}
\hline مندلى & Facebook & توئيت & شبكههاى اجتماعى \\
\hline $99 \mathrm{~V}$ & $\Delta T$ & 10 . & تعداد مقالات \\
\hline
\end{tabular}

جدول f f

\begin{tabular}{|c|c|c|c|c|c|}
\hline & متغيرها & استفاده & كسب & بحث & رسانههاى اجتماعى \\
\hline \multirow{3}{*}{$\begin{array}{l}\text { استنادهاى بايعاه } \\
\text { Scopus }\end{array}$} & Pearson correlation & .1 .94 & $\cdot /$ / &.$- / \cdot \uparrow$ & .11 .9 \\
\hline & $\operatorname{Sig}(2$-tail) & $\cdot / \mu \cdot$ & $.1 \ldots$ & /Ar. & ./rav \\
\hline & $\mathrm{N}$ & T\&1 & rDS & $r \Delta$ & 91 \\
\hline
\end{tabular}

بلهور عمده بلمواردى مانند: مشاهدات، كليك و دانلود

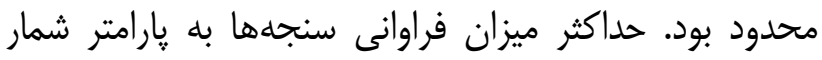
خوانندگان كه زيرمجموعه شاخص كسب است تعلق داشت؛

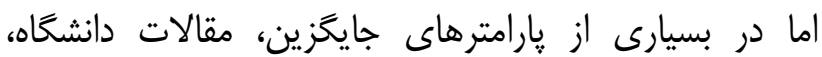

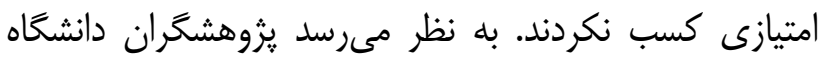

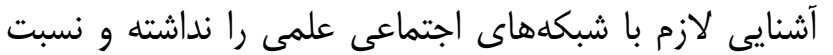

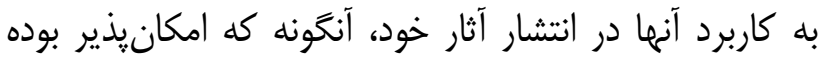

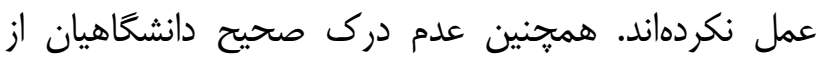
موضوع ترجمان دانش (بيان مفاهيم تخصصى به زبان ساده) در قالب شبكههاى اجتماعى را مىتوان در اين زمينه مؤثر دانست.

مقالات دانشگاه علوم يزشكى بيرجند بيشترين ميزان

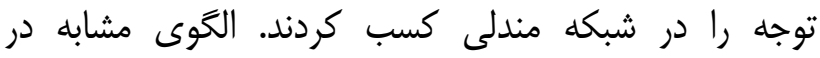

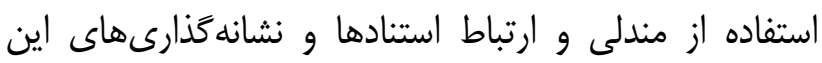

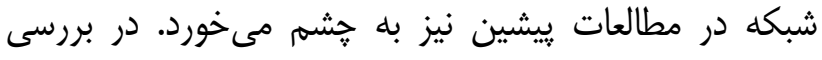

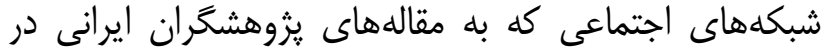

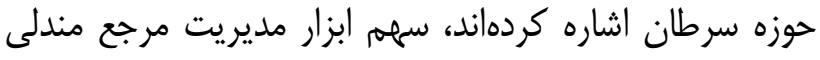

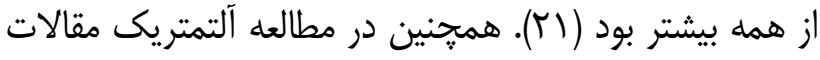
علمى حوزه سواد سلامت در رسانههاى اجتماعى، بيشترين

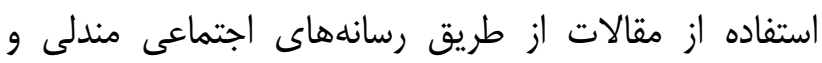
Twitter

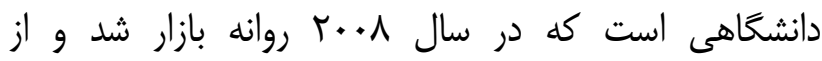

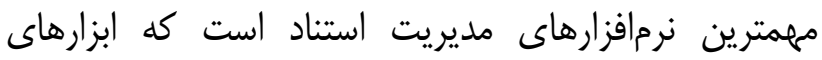

از ميان شبكههاى اجتماعى كه در يايعاه Scopus رصد

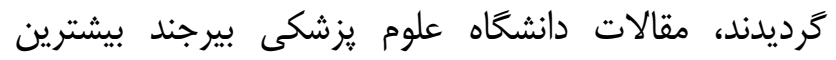
ميزان توجه را با اختلاف زياد در شبكه مندلى (Mendeley) كسب كردند (جدول rا). نتايج آزمون همبستخى ييرسون حاكى از آن بود بود كه بين

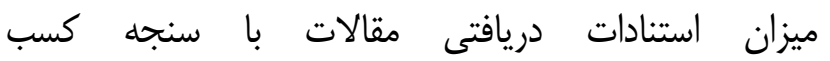

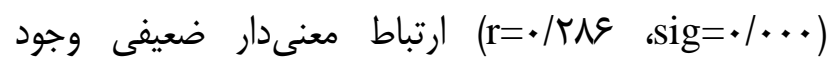
داشت. اين ارتباط بلهترتيب با سنجههاى رسانههاى اجتماعى

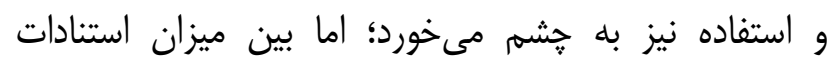

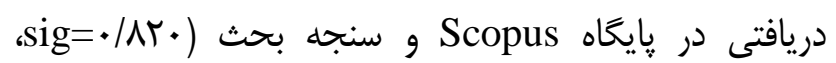

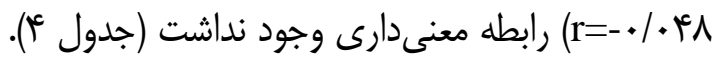

بررسى شاخصهاى آلتمتريكس مرتبط با مقالات

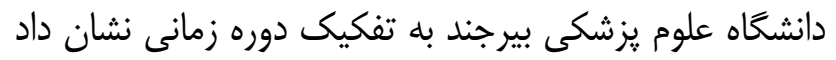

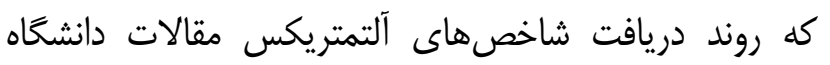
علوم يزشكى بيرجند در سالهاى مختلف بر اساس نظام

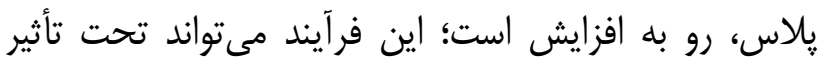

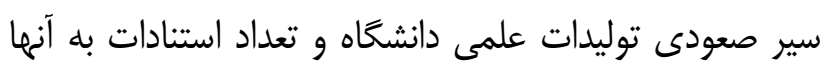

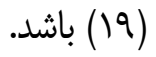

ميزان توجه به مقالات دانشگاه براساس نظام PlamX

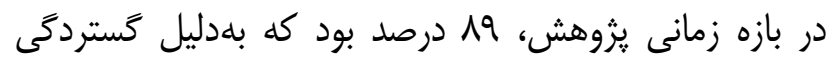
شاخصها و يارامترهاى نظام plamX به دست آمده است و و 
آلتمتريكس در راستاى ارزيابى يزوهش در اختيار كذاشت و

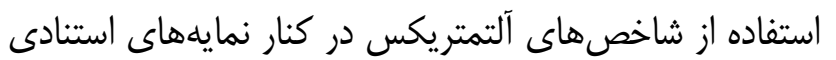

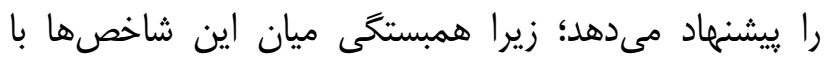

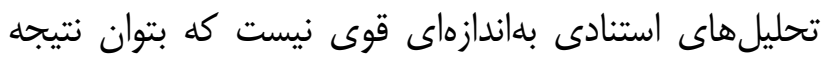
كرفت كه هر دو تصاويرى يكسان از واقعيت اثركذارى

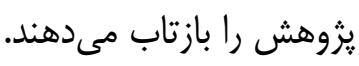

\section{نتيجه Fيرى}

شاخصهاى آلتمتريكس يا سنجههاى جايگزين، مكمل

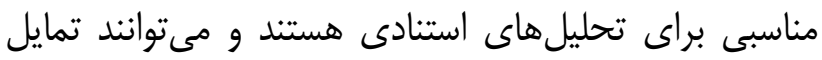

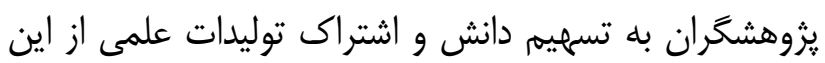

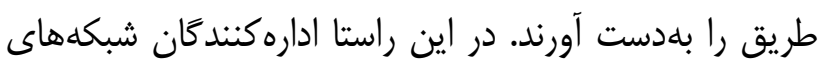

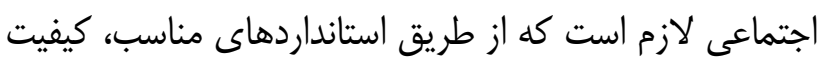

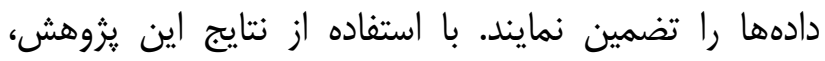

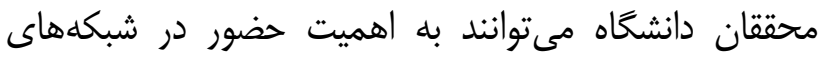

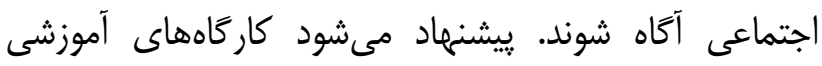
بلمنظور معرفى و آموزش استفاده از شبكههاى اجتماعى ئلى

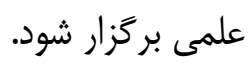

\section{تقلدير و تشكر}

نويسندكان لازم معىدانند از حمايت معاونت محترم تحقيقات و فناورى در انجام اين مطالعه قدردانى نمايند.

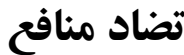

نويسندگًان مقاله اعلام مىدارند كه هيجگَّنه تضاد

$$
\text { منافعى در يزوهش حاضر وجود ندارد. }
$$

آلتمتريك را فراهم آورده و به يزوهشگران امكان سازماندهى يزوهشهاى شخصى را مى دهد؛ همجنين قابليت تأييد هويّت

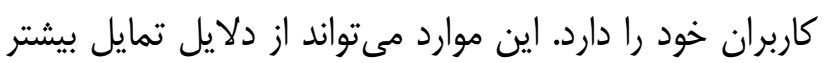

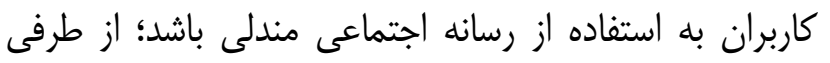
عدم امكان دسترسى بله برخى از رسانههاى اجتماعى در داخل

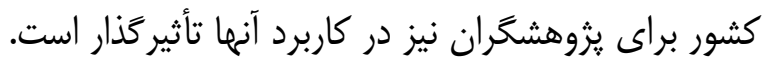

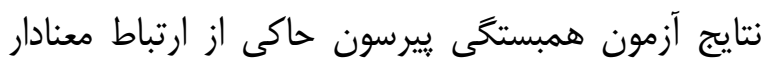

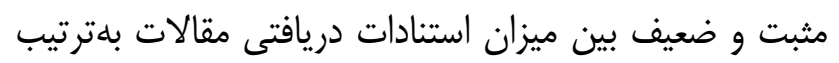
با: سنجه كسب، رسانهاى اجتماعى و استفاده بود؛ يعنى هر مر معنى

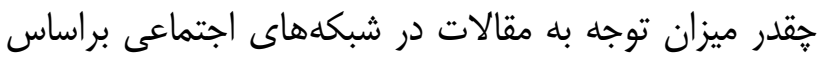
يارامترهاى شاخص كسب (شمار خوانندكان، مشتركين، عاقمندىها و ...) و نيز رسانههاى اجتماعى (توئيتها،

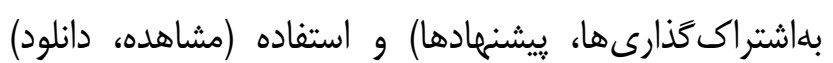

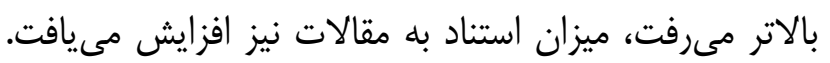
شدت و ضعف رابطه بين سنجههاى مختلف و مئن ميزان

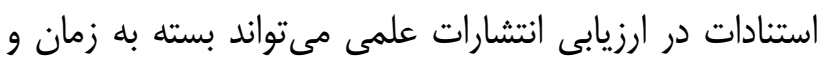

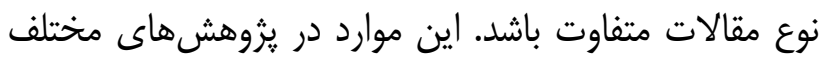

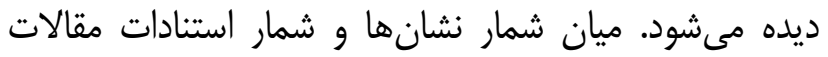

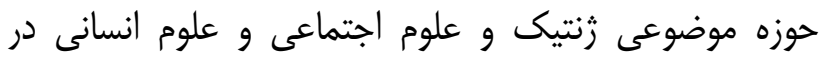
مندلى همبستخى متوسطى مشاهده شده است (r)؛ همجٍنين

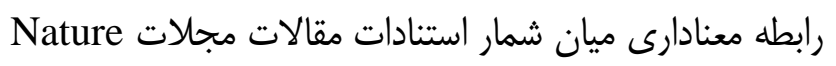

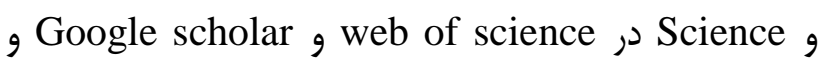
شمار نشانها در سايت ULike و مندلى ززارش شده است

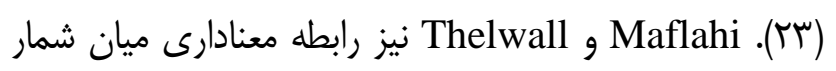

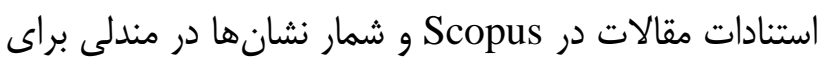
جهار مجله حوزه علم اطلاعات و كتابدارى يافتند (بآب).

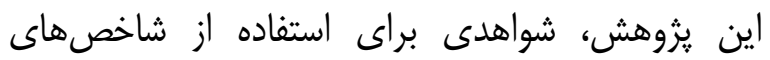

1- Mas-Bleda A, Thelwall M, Kousha K, Aguillo IF. Do highly cited researchers successfully use the social web? Scientometrics. 2014; 101(1): 337-56.

2- Haustein S, Siebenlist T. Applying social bookmarking data to evaluate journal usage. J Informetr. 2011; 5(3): 44657. doi: 10.1016/j.joi.2011.04.002

3- Mohammadi E, Thelwall M. Mendeley readership altmetrics for the social sciences and humanities: Research evaluation and knowledge flows. J Assoc Inf Sci Technol. 2014; 65(8): 1627-38. doi: 10.1002/asi.23071 
4- Sotoudeh H, Ravaei M, Mirzabeigi M. Comparing the opportunities provided by altmetrics and citation analysis for research evaluation. Iranian journal of information processing and management. 2018; 34(1): 113-38.

5- Donato H. Traditional and alternative metrics: The full story of impact. Rev Port Pneumol. 2014; 20(1): 1-2. doi: 10.1016/j.rppneu.2013.11.001

6- Priem J, Piwowar HA, Hemminger BH. Altmetrics in the wild: Using social media to explore scholarly impact. ArXiv. 2012; 1203.4745v1. Available at: https://arxiv.org/html/1203.4745

7- Trueger NS, Thoma B, Hsu CH, Sullivan D, Peters L, Lin M. The altmetric score: A new measure for article-level dissemination and impact. Ann Emerg Med. 2015; 66(5): 549-53. doi: 10.1016/j.annemergmed.2015.04.022.

8- Buschman M, Michalek A. Are alternative metrics still alternative? Bull Am Soc Inf Sci. 2013; 39(4): 35-9. doi: 10.1002/bult.2013.1720390411

9- Konkiel S, Scherer D. New opportunities for repositories in the age of altmetrics. Bull Am Soc Inf Sci. 2013; 39(4): 22-6. doi: 10.1002/bult.2013.1720390408

10- Sud P, Thelwall M. Evaluating altmetrics. Scientometrics. 2014; 98(2): 1131-43.

11- Bornmann L. Do altmetrics point to the broader impact of research? An overview of benefits and disadvantages of altmetrics. Journal of informetrics. 2014; 8(4): 895-903.

12- Roemer RC, Borchardt R. From bibliometrics to altmetrics: A changing scholarly landscape. C\&RL News. 2012; 73(10): 596-600. doi: 10.5860/crln.73.10.8846

13- Bashiri T, Erfanmanesh MA, Asnafi A. Do Highly-Cited Articles from Iran in the Field of Medical Sciences Attract High Attentions in Social Media? Health Information Management Journal. 2018; 15(2): 89-95. [Persian] DOI: 10.22122/him.v15i2.3445

14- Kolahi J, Iranmanesh P, Khazaei S. Altmetric analysis of 2015 dental literature: a cross sectional survey. Br Dent J. 2017; 222(9): 695-9. doi: 10.1038/sj.bdj.2017.408.

15- Goltaji M, Jowkar A. Presence of scientific outputs of medical informatics in social media: An altmetric study. Health Inf Manage. 2017; 14(2): 71-7. [Persian]

16- Esmaeilpour-Bandboni M, Batooli Z, Ramezani A, Ranjbar-Pirmousa Z, Ramezani F. An Assessment of Altmetrics Indicators on Citation Rate of Articles Affiliated by Guilan University of Medical Sciences. Health Inf Manage. 2017; 13(5): 367-72. [Persian]

17- Wang J, Alotaibi NM, Ibrahim GM, Kulkarni AV, Lozano AM. The spectrum of altmetrics in neurosurgery: the top 100 "Trending" articles in neurosurgical journals. World Neurosurg. 2017; 103: 883-95. e1. doi: 10.1016/j.wneu.2017.04.157.

18- Barbic D, Tubman M, Lam H, Barbic S. An analysis of altmetrics in emergency medicine. Acad Emerg Med. 2016; 23(3): 251-68. doi: 10.1111/acem.12898.

19- Ehtesham H. Evaluation of scientific output of researchers at Birjand University of Medical Sciences in web of science during 2000-2011. J Birjand Univ Med Sci. 2012; 19(3): 324-31. [Persian]

20- Bornmann L. Validity of altmetrics data for measuring societal impact: A study using data from Altmetric and F1000Prime. Journal of Informetrics. 2014; 8(4): 935-50. doi: 10.1016/j.joi.2014.09.007

21- Asemi A, BasirianJahromi R, SeyyedHosseini S. The Rate of Attention to Iranian Papers Published on Common Cancers in Social Networks: An Altmetrics Approach. J Health Adm. 2018; 21(73): 72-88. [Persian]

22- Serati Shirazi M, Goltaji M. An Altmetric Study on Scientific Articles of "Health Literacy" in Social Media. Payesh. 2018; 17(3): 249-56. [Persian]

23- Li X, Thelwall M, (eds). F1000, Mendeley and traditional bibliometric indicators. Proceedings of the 17th international conference on science and technology indicators; 2012: Science-Metrix and OST Montréal, Canada.

24- Maflahi N, Thelwall M. When are readership counts as useful as citation counts? S copus versus M endeley for LIS journals. J Assoc Inf Sci Technol. 2016; 67(1): 191-9. doi: 10.1002/asi.23369 